\title{
Time to seroconversion of HBsAg to anti-HBs in individuals who lost HBsAg during follow-up
}

\author{
M. R. H. ROUSHAN ${ }^{1}$, M. MOHAMMADPOUR ${ }^{1}$, M. BAIANY ${ }^{1}$, S. SOLEIMANI ${ }^{2}$ \\ AND A. BIJANI ${ }^{1}$ \\ ${ }^{1}$ Infectious Diseases and Tropical Medicine Research Centre, Babol University of Medical Sciences, Babol, Iran \\ ${ }^{2}$ Razi Institute of Pathobiology, Modares Avenue, Babol, Iran
}

Received 31 December 2015; Accepted 26 May 2016; first published online 8 June 2016

\section{SUMMARY}

To determine the time to appearance of antibody against hepatitis B surface antigen (anti-HBs) after clearance of hepatitis B surface antigen (HBsAg) in chronically infected individuals, we followed up 3963 cases with positive antibody against hepatitis B e antigen (anti-HBe) from 1991 to 2014. Of these, 101 (67 males, 34 females) lost HBsAg. These serocleared cases were checked every 6-month interval regarding $\mathrm{HBsAg}$, anti-HBs, liver function tests, and liver sonography. Hepatitis B virus DNA was assessed at the time of seroclearance or the appearance of anti-HBs. The mean age of these patients at entry to this study was $34.4 \pm 13$ years. The mean follow-up duration until seroclearance of HBsAg was $6 \cdot 6 \pm 4 \cdot 3$ years. After the mean follow-up of $43 \cdot 7 \pm 45$ months, anti-HBs appeared in $64(63 \cdot 4 \%)$ cases. The cumulative probabilities of anti-HBs appearance for 2,5 and 10 years were $24 \cdot 3 \%, 58 \%$ and $78 \cdot 2 \%$, respectively. The appearance of anti-HBs was associated with age $\geqslant 35$ years and seroclearance of HBsAg (hazard ratio 1.96, $95 \%$ confidence interval $1 \cdot 32-3 \cdot 38, P=0 \cdot 016$ ) but not with sex. The results show that anti-HBs may develop in $78 \cdot 2 \%$ of cases within 10 years of $\mathrm{HBsAg}$ clearance. Age $\geqslant 35$ years at $\mathrm{HBsAg}$ loss was associated with earlier development of anti-HBs.

Key words: Clearance, chronic hepatitis B, follow-up, HBsAg, resolved hepatitis B.

\section{INTRODUCTION}

More than 400 million people in the world are chronically infected with hepatitis B virus (HBV) and are at risk of developing cirrhosis and hepatocellular carcinoma. These individuals are the main source of HBV infection worldwide $[1,2]$. The natural history of chronic HBV infection can be divided into five phases: immune tolerance, immune reactive hepatitis $B$ e antigen $(\mathrm{HBeAg})$-positive, inactive HBV carrier state,

\footnotetext{
* Author for correspondence: Dr M. R. H. Roushan, Infectious Diseases and Tropical Medicine Research Centre, Babol University of Medical Sciences, Babol 4717641367, Iran. (Email: hagar2q@yahoo.ca)
}

HBeAg-negative chronic hepatitis $\mathrm{B}$, and hepatitis $\mathrm{B}$ surface antigen (HBsAg)-negative [3]. Annually, between $0.5 \%$ and $3 \%$ of inactive HBV carriers lose HBsAg [4-7]. Spontaneous HBsAg clearance usually confers a good prognosis if there is no pre-existing hepatocellular carcinoma or cirrhosis at the time of HBsAg seroclearance [8-11].

Seroconversion to antibody against hepatitis B surface antigen (anti-HBs) following HBsAg loss is more likely to prevent the progression of chronic liver diseases to cirrhosis and hepatocellular carcinoma and it represents immunity to $\mathrm{HBV}$ and may indicate a better prognosis $[1,2,12]$. Antibodies to HBsAg develop within 6 months in $95 \%$ cases with acute hepatitis $\mathrm{B}$, but the development of anti-HBs in patients 
with chronic HBV infection who lost HBsAg during follow-up has not been clearly determined [12]. This study was conducted to determine the time to appearance of anti-HBs in inactive HBV carriers who lost HBsAg during follow-up.

\section{METHODS}

From 1991 to 2014, 3963 cases of inactive anti-HBepositive carriers were registered at the Infectious Diseases and Tropical Medicine Research Centre of Babol University of Medical Sciences. Patients with normal levels of aminotransferases, absence or low levels of serum HBV DNA on two occasions for 1 year plus normal liver sonographic findings were considered to be inactive HBV carriers [3, 13]. Patients co-infected with hepatitis $\mathrm{C}, \mathrm{D}$, previous history of treatment with anti-hepatitis agents, HIV, alcohol consumer and intravenous drug user were excluded from the study.

After enrolment, these cases were checked at 6-month intervals regarding viral markers (HBsAg, anti-HBs), liver function tests [serum aspartate aminotransferase (AST), alanine aminotransferase (ALT)], $\alpha$-fetoprotein, complete blood count and platelet count. Liver sonography was also performed for those aged $>40$ years and for those with a history of cirrhosis or liver cancer in their family members due to a HBV-related cause. The viral markers were tested by ELISA (HBsAg, Siemens, Germany; anti-HBs, Radim, Italy). A record was prepared for each patient and the variables were noted.

Those who lost HBsAg during follow-up, tested on two occasions at 6-month intervals, were entered into the study analysis (time of seroclearance). In these cases, serum HBV DNA levels were measured at the time of seroclearance and the appearance of antiHBs, as well as in those who had elevated ALT or AST levels during the follow-up period. For isolation of HBV DNA, we used the QIAamp DNA mini-kit (Qiagen, Germany). All processes were performed according to the manufacturer's instructions. For quantification of HBV DNA, we used Rotor-Gene 3000 (Corbett Research, Australia) using the Artus HBV RG PCR kit (Qiagen, Germany). According to the manufacturer's instructions, the sensitivity of the test was $3.8 \mathrm{IU} / \mathrm{ml}$ ( $1 \mathrm{IU}=7$ copies $/ \mathrm{ml})$. The study was approved by the Infectious Diseases and Tropical Medicine Research Centre of Babol University of Medical Sciences and the ethical committee approved the study.

\section{Statistical analysis}

The data were collected and analysed using SPSS v. 22 (IBM Corp., USA). The $t$ test was used to compare mean values. A multiple Cox proportional hazards regression model was used to estimate HBsAg to antiHBs with the covariates of sex, and seroclearance age $<35$ or $\geqslant 35$ years. The time to appearance of anti-HBs data was plotted using a Kaplan-Meier graph. The log-rank test was used to compare the appearance of anti-HBs with the same covariates. Differences with a $P$ value $<0.05$ were considered significant. All $P$ values were two-tailed.

\section{RESULTS}

During follow-up, 119 (3\%) subjects became HBsAg negative and 18 cases did not attend the follow-up and were excluded from the study. Thus, data from 101 subjects (67 males, 34 females) were analysed. None had seroreverted to HBsAg positive.

The mean age of patients at entry to the study was $34 \cdot 4 \pm 13$ years (range 11-64 years). The mean duration of follow-up before seroclearance of HBsAg in these cases was $6 \cdot 6 \pm 4 \cdot 3$ years (range $1-22$ years). The mean age of the 67 males was $35.7 \pm 13.8$ and of the 34 females $31 \cdot 8 \pm 10 \cdot 7$ years $(P=0 \cdot 16)$.

Anti-HBs developed in 40 males with a mean follow-up period of $47 \cdot 6 \pm 48$ months and in 24 females with a mean follow-up period of $49 \cdot 3 \pm 47 \cdot 8$ months after seroclearance of HBsAg $(P=0.89)$. The cumulative probabilities for the appearance of anti-HBs after the seroclearance of HBsAg for 1, 2, 3,4 , and 5 years were $8 \cdot 7 \%, 24 \cdot 3 \%, 37 \%, 49 \cdot 1 \%$, and $58 \%$ cases, respectively (Fig. 1). Anti-HBs developed in $78 \cdot 2 \%$ of subjects within 10 years of seroclearance. The mean duration of seroconversion in these cases after seroclearance was $43 \cdot 7 \pm 45$ months (range 6-215 months). Cox regression model showed that sex had no effect on the appearance of antiHBs, but age $\geqslant 35$ years after seroclearance was associated with the appearance of anti-HBs (hazard ratio $1 \cdot 96,95 \%$ confidence interval $1 \cdot 32-3 \cdot 38, P=0 \cdot 016$ ) (Table 1, Fig. 2).

HBV DNA was detected in $16(15 \cdot 8 \%)$ out of 101 cases at the time of seroclearance. After seroconversion, HBV DNA was detected in six $(9 \cdot 5 \%)$ out of 63 subjects who developed anti-HBs. ALT levels in all cases were in the normal range except in nine cases that had serum ALT levels $<80$ IU/1 on occasions during follow-up, but sonography in these 


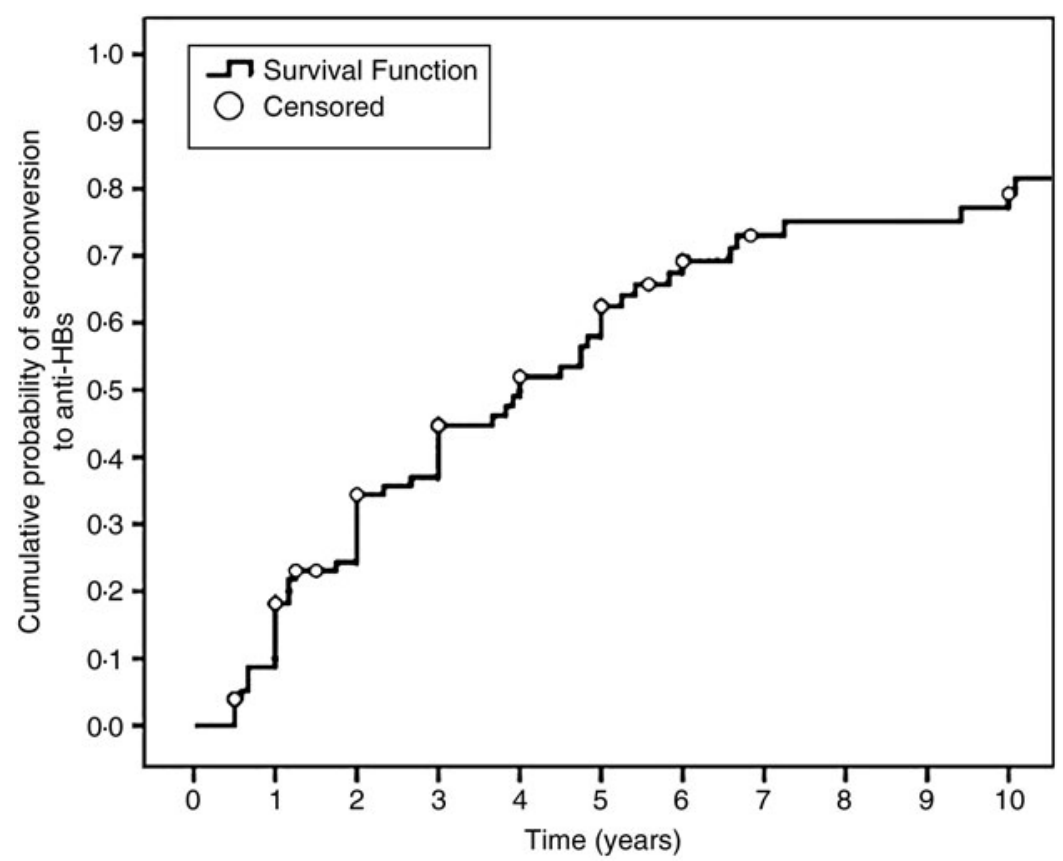

Fig. 1. Cumulative probability of seroconversion to antibody against hepatitis B surface antigen (anti-HBs) after seroclearance of hepatitis B surface antigen (HBsAg).

Table 1. Estimated time to seroconversion of anti-HBs after seroclearance of HBsAg and hazard ratio regarding sex and age $<35$ or $\geqslant 35$ years

\begin{tabular}{|c|c|c|c|c|c|c|}
\hline Variable & $\begin{array}{l}\text { Mean ST } \\
(95 \% \mathrm{CI})\end{array}$ & $\begin{array}{l}\text { Median ST } \\
(95 \% \mathrm{CI})\end{array}$ & $\begin{array}{l}\text { Crude HR } \\
(95 \% \mathrm{CI})\end{array}$ & $P$ value & $\begin{array}{l}\text { Adjusted HR } \\
(95 \% \mathrm{CI})\end{array}$ & $P$ value \\
\hline \multicolumn{7}{|l|}{ Sex } \\
\hline Female & $65 \cdot 8(40 \cdot 7-90 \cdot 9)$ & $48(31 \cdot 9-64 \cdot 1)$ & 1 & & 1 & \\
\hline Male & $70 \cdot 2(51 \cdot 7-88 \cdot 6)$ & $48(28 \cdot 1-67 \cdot 9)$ & $0.96(0 \cdot 57-1 \cdot 61)$ & $0 \cdot 88$ & $0 \cdot 88(0 \cdot 52-1 \cdot 48)$ & $0 \cdot 641$ \\
\hline \multicolumn{7}{|l|}{ Age (years) } \\
\hline$<35$ & $89 \cdot 7(62 \cdot 7-116 \cdot 7)$ & $72(43 \cdot 6-100 \cdot 4)$ & 1 & & 1 & \\
\hline$\geqslant 35$ & $53 \cdot 7(38 \cdot 3-69 \cdot 2)$ & $36(25 \cdot 6-46 \cdot 4)$ & $1 \cdot 92(1 \cdot 12-3 \cdot 30)$ & $0 \cdot 018$ & $1 \cdot 96(1 \cdot 32-3 \cdot 38)$ & $0 \cdot 016$ \\
\hline Total & $68 \cdot 2(53 \cdot 3-83 \cdot 1)$ & $48(28 \cdot 2-67 \cdot 8)$ & - & - & - & - \\
\hline
\end{tabular}

Anti-HBs; Antibody against hepatitis B surface antigen; HBsAg; hepatitis B surface antigen; ST, Survival time; CI, confidence interval; HR, hazard ratio.

cases showed mild fatty liver and their HBV DNA levels were $<2000$ copies/ml. No cirrhosis or hepatocellular carcinoma were found at the time of seroclearance or afterwards.

\section{DISCUSSION}

The ideal goal for inactive HBV carriers is seroclearance of HBsAg and the appearance of anti-HBs. So far, studies with the aim of producing anti-HBs after seroclearance of HBsAg have not been published in the medical literature, and we believe that the present study may be the first report showing the follow-up of a significant number of cases with chronic HBV infection who lost HBsAg during follow-up. Although spontaneous clearance of HBsAg usually confers a good prognosis in those without pre-existing hepatocellular carcinoma or cirrhosis at the time of HBsAg seroclearance $[9,10]$, other studies have shown cirrhosis and hepatocellular carcinoma in patients who were cirrhotic or non-cirrhotic at the time of HBsAg clearance [14-20]. In our study, we found that $78 \cdot 2 \%$ of inactive HBV subjects who lost HBsAg during followup seroconverted to anti-HBs within 10 years. 


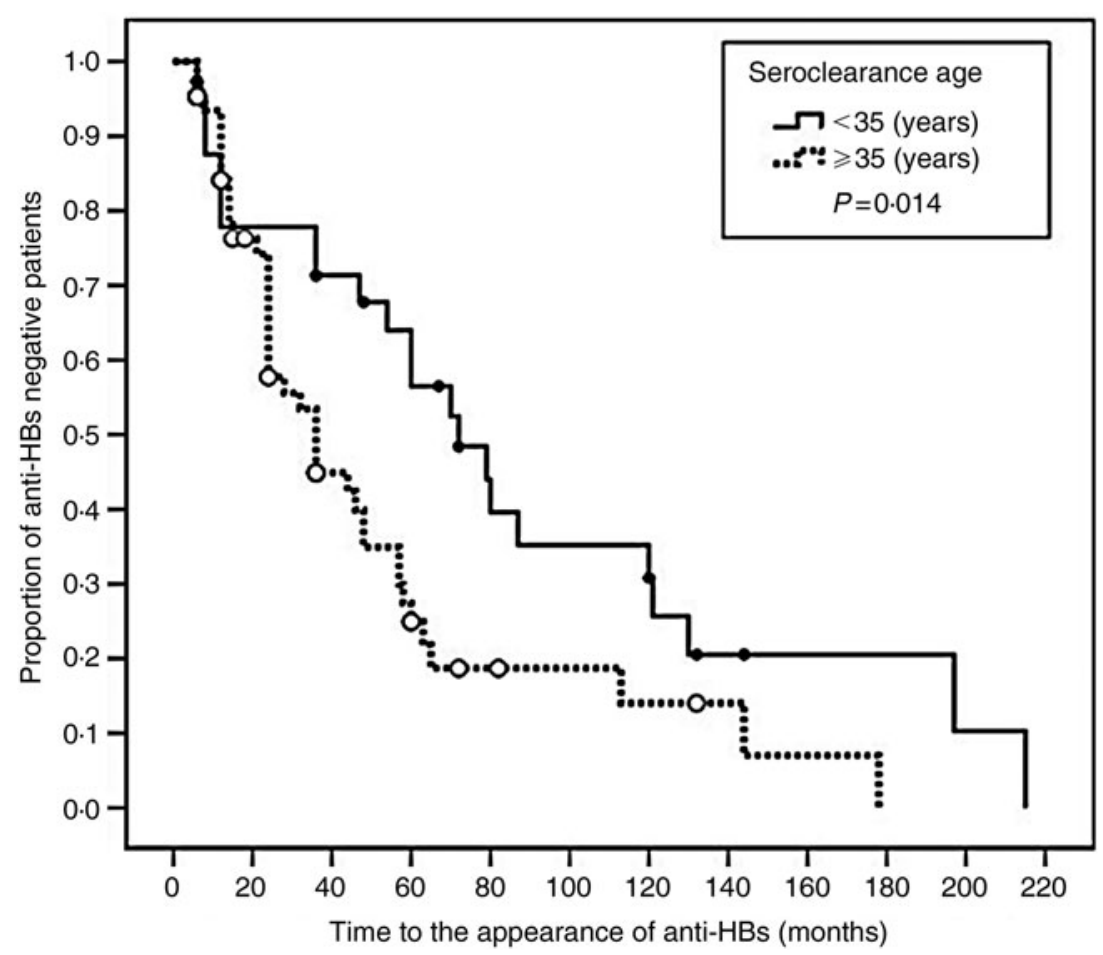

Fig. 2. Age $\geqslant 35$ years and seroclearance of hepatitis $B$ surface antigen (HBsAg) was associated with earlier appearance of antibody against hepatitis B surface antigen (anti-HBs) than for individuals aged $<35$ years.

Development of anti-HBs may be a clue which shows that they have protection and are less likely to predispose to the development of chronic hepatitis, cirrhosis and hepatocellular carcinoma [1, 2]. In our series of cases, we did not find these complications at the time of seroclearance of HBsAg, or during the followup period. In contrast to acute hepatitis B cases, in which anti-HBs develops within 6 months of the initiation of infection, in those with chronic HBV infection, seroconversion to anti-HBs may develop at 1 year after HBsAg clearance in a minority of cases.

Arase et al. [8] reported that development anti-HBs was seen in $50 \cdot 2 \%$ of patients with spontaneous seroclearance of HBsAg at the fifth year after HBsAg seroclearance. In our study, after the mean follow-up of $43 \cdot 7 \pm 45$ months, anti-HBs developed in $64(63 \cdot 4 \%)$ cases and no patients developed cirrhosis or hepatocellular carcinoma, which is in agreement with the results obtained by Chen et al. [10]. In our study, we found that $8.7 \%$ of cases seroconverted to anti-HBs within 12 months of seroclearance of HBsAg, which was lower than the results obtained in previous studies of $11 \cdot 4 \%$ and $16 \cdot 7 \%$ [19, 21].

An interesting finding in our study was that individuals who had HBsAg seroclearance after age $\geqslant 35$ years had a lower mean time-span for the appearance of anti-HBs compared to individuals aged $<35$ years (Fig. 2, Table 1). Therefore, the older the age of the patient at the time of seroclearance, the more likely they are to develop anti-HBs, a finding that has not been reported previously.

Yuen et al. [21] showed that if HBsAg seroclearance occurred before age 50 years, these patients would have a significantly lower risk of developing cirrhosis or HCC since we saw no cirrhosis or cancer in the follow-up of our cases. Ferreira et al. [22] followed-up 548 cases of chronic HBV infection for 15 years and they found that 40 cases lost HBsAg with no progression to more severe forms of the disease during followup and the results were similar to thos obtained in our study.

It is of interest that $63.4 \%$ of carriers who became HBsAg negative developed anti-HBs, suggesting that the remaining $36.6 \%$ cases of $\mathrm{HBV}$ infection were not cleared, and HBsAg production decreased below the sensitivity of the detection methods. Other findings of our study were the detection of HBV DNA in 16 $(15.8 \%)$ out of 101 cases at the time of seroclearance of $\mathrm{HBsAg}$ and that the majority of patients had persistently undetectable HBV DNA levels during follow-up. Similar to our study, taken within 1 year after HBsAg seroclearance, other studies found that 
up to $13 \cdot 4 \%$ of cases had detectable HBV DNA with low viral loads $[18,21]$.

With the appearance of anti-HBs, we observed low levels of HBV DNA ( $<100$ copies $/ \mathrm{ml})$ in a small number of our cases. Low viral load, genotypes B, C and lengthy duration of $\mathrm{HBV}$ infection were associated with HBsAg seroclearance [6, 23]. Earlier studies [8, $16,24]$ reported HBV DNA in $31-71.4 \%$ of cases at the time of HBsAg seroclearance, which decreased to $21.4 \%$ after 5 years, and $14.3 \%$ after 10 years. The weakness of the present study is that we did not determine the precise presence or absence of liver fibrosis because asymptomatic carriers are not required to be evaluated regarding liver fibrosis [3]. Long-term follow-up of these seroconverted subjects is necessary to see the clinical outcome. In conclusion, the results show that anti-HBs may develop in up to $78 \%$ of cases of anti-HBe-positive chronic carriers of hepatitis B. Age $\geqslant 35$ years at HBsAg seroclearance was associated with the earlier development of anti-HBs.

\section{ACKNOWLEDGEMENTS}

The authors are grateful to all the patients who participated in the study. Thanks are due to Dr Evangeline Foronda for English editing and to Dr Soraya Khafri for performing the statistical analysis.

This study was financially supported by the Infectious Diseases and Tropical Medicine Research Centre, Babol University of Medical Sciences, Babol, Iran (grant no. 1321/1390).

\section{DECLARATION OF INTEREST}

None.

\section{REFERENCES}

1. Sorrell MF, et al. National Institutes of Health Consensus Development Conference Statement: management of hepatitis B. Annals of Internal Medicine 2009; 150: 104-110.

2. Lavanchy D. Hepatitis B virus epidemiology, disease burden, treatment, and current and emerging prevention and control measures. Journal of Viral Hepatology 2004; 11: 97-107.

3. Papatheodoridis G, et al. EASL Clinical Practice Guidelines: management of chronic hepatitis B virus infection. Journal of Hepatology 2012; 57: 167-185.

4. Villa E, et al. Natural history of chronic HBV infection: special emphasis on the prognostic implications of the inactive carrier state versus chronic hepatitis. Digestive and Liver Disease 2011; 43S: S8-S14.
5. McMahan BJ, et al. Serologic and clinical outcomes of 1536 Alaska Natives chronically infected with hepatitis B virus. Annals of Internal Medicine 2001; 135: 759-768.

6. Kim JH, et al. Factors associated with natural seroclearance of hepatitis B surface antigen and prognosis after seroclearance: a prospective follow-up study. Hepatogastroenterology 2008; 55: 578-581.

7. Simonetti J, et al. Clearance of hepatitis B surface antigen and risk of hepatocellular carcinoma in a cohort chronically infected with hepatitis B virus. Hepatology 2010; 51: 1531-1537.

8. Arase Y, et al. Long-term outcome after hepatitis B surface antigen seroclearance in patients with chronic hepatitis B. American Journal of Medicine 2006; 119: e9-16.

9. Ahn SH, et al. Long-term clinical and histological outcomes in patients with spontaneous hepatitis B surface antigen seroclearance. Journal of Hepatology 2005; 42: 188-194.

10. Chen YC, et al. Prognosis following spontaneous HBsAg seroclearance in chronic hepatitis B patients with or without concurrent infection. Gastroenterology 2002; 123: 1084-1089.

11. Chu CM, Liaw YF. HBsAg seroclearance in asymptomatic carriers of high endemic area: appreciably high rates during a long term follow up. Hepatology 2007; 45: 1187-1192.

12. Liaw YF, et al. Incidence, determinants and significance of delayed clearance of serum HBsAg in chronic hepatitis B virus infection:a prospective study. Hepatology 1991; 13: 627-631.

13. Thio CL, Hawkins C. Hepatitis B virus and hepatitis delta virus. In: Bennett JE, Dolin R, Blaser MJ, eds. In: Mandell, Douglas, and Bennett's Principles and Practice of Infectious Disease, 18th edn. Canada: Elsevier Saunders, 2015, pp. 1815-1839.

14. Fattovich G, et al. Delayed clearance of serum HBsAg in compensated cirrhosis $\mathrm{B}$ : relation to interferon alpha therapy and disease prognosis. American Journal of Gastroenterology 1998; 93: 896-900.

15. Yuen MF, et al. HBsAg seroclearance in chronic hepatitis B in the Chinese: virology, histological and clinical aspects. Hepatology 2004; 39: 1694-1701.

16. Huo TI, et al. Seroclearance of hepatitis B surface antigen in chronic carriers does not necessarily imply a good prognosis. Hepatology 1999; 28: 231-236.

17. Draelos M, et al. Significance of isolated antibody to hepatitis B core antigen determined by immune response to hepatitis $\mathrm{B}$ vaccination. Journal of the American Medical Association 1987; 258: 1193-1195.

18. Manno M, et al. Natural history of chronic HBV carriers in Northern Italy: morbidity and mortality after 30 years. Gastroenterology 2004; 127: 756-763.

19. Chen YC, et al. Decreasing levels of HBsAg predict $\mathrm{HBsAg}$ seroclearance in patients with inactive chronic hepatitis B virus infection. Clinical Gastroenterology and Hepatology 2012; 10: 297-302.

20. Kim GA, et al. Incidence of hepatocellular carcinoma after HBsAg seroclearance in chronic hepatitis B 
patients: a need for surveillance. Journal of Hepatology 2014; 62: 1092-1099.

21. Yuen MF, et al. HBsAg seroclearance in chronic hepatitis B in Asian patients: replicative level and risk of hepatocellular carcinoma. Gastroenterology 2008; 135: 1192-1199.

22. Ferreira SC, et al. Factors associated with spontaneous HBsAg clearance in chronic hepatitis B patients followed at a university hospital. Annals of Hepatology 2014; 13: 762-770.

23. Liu J, et al. Spontaneous seroclearance of hepatitis B seromarkers and subsequent risk of hepatocellular carcinoma. Gut 2014; 63: 1648-57.

24. Adachi H, et al. Clearance of HBsAg in seven patients with chronic hepatitis B. Hepatology 1992; 16: 1334 1337 . 